\title{
O lúdico no ensino de biologia celular: possibilidades no ensino superior
}

\author{
Nadja Biondine Marriel ${ }^{1}$, Luiz Carlos Maia Ladeira ${ }^{2}$, Renan dos Santos \\ Araújo $^{3}$, Janaina da Silva ${ }^{4}$, Ana Luiza Pereira Martins ${ }^{5}$, Mara Garcia Tavares ${ }^{6}$
}

\begin{abstract}
Resumo: Considerando as dificuldades que alguns alunos recém-ingressos na Universidade apresentam para compreender conceitos abstratos, este trabalho descreve um curso de extensão, na área de Biologia Celular, que foi realizado com o objetivo de contribuir para a aprendizagem efetiva de um grupo de graduandos da Universidade Federal de Viçosa (MG). O trabalho relata também a importância da experiência vivenciada para os pós-graduandos que ministraram o mesmo. No Curso foram utilizadas atividades lúdicas diversificadas, escolhidas de acordo com o tema que seria abordado. Os resultados mostraram que as atividades desenvolvidas foram muito bem aceitas pelos graduandos, ajudando na compreensão dos conteúdos, através de um processo agradável e acessível, que viabilizou a construção dos saberes. Para os discentes da pós-graduação, a experiência foi única e contribuiu para a formação profissional dos mesmos. Portanto, os resultados obtidos foram significativos para todos os envolvidos.
\end{abstract}

Palavras-chave: Aprendizagem significativa. Extensão universitária. Metodologias ativas.

Área Temática: Educação.

\section{Playfulness in the Teaching of Cell Biology: possibilities in higher education}

\begin{abstract}
I: Considering the difficulties that some new students at the University present to understand abstract concepts, this work describes an extension course, in the area of Cell Biology, which was carried out with the objective of contributing to the effective learning of a group of undergraduate students at the University Federal University of Viçosa (MG). The work also reports the importance of the experience lived for the graduate students who taught the Course. In the Course, diversified recreational activities were used, chosen according to the theme that would be approached. The results showed that the process was very well accepted by the students, helping them to understand the contents, through a pleasant and accessible process, which enabled the construction of knowledge. For graduate students, the experience was unique and contributed to their professional training. Therefore, the results were significant for everyone involved.
\end{abstract}

Keywords: Meaningful learning. University extension. Active methodologies.

\footnotetext{
${ }^{1}$ Doutora em Biologia Celular e Estrutural pela Universidade Federal de Viçosa, Campus Viçosa (MG), Brasil. Email: nadja_marriel@yahoo.com.br ${ }^{2}$ Mestre em Biologia Celular e Estrutural pela Universidade Federal de Viçosa, Campus Viçosa (MG), Brasil. Email: luizmaialadeira@ gmail.com ${ }^{3}$ Doutor em Biologia Celular e Estrutural pela Universidade Federal de Viçosa, Campus Viçosa (MG), Brasil. Email: renandosantosaraujo@gmail.com ${ }^{4}$ Mestre em Biologia Celular e Estrutural pela Universidade Federal de Viçosa, Campus Viçosa (MG), Brasil. Email: janacbio18@gmail.com ${ }^{5}$ Mestre em Biologia Celular e Estrutural pela Universidade Federal de Viçosa, Campus Viçosa (MG), Brasil. Email: analuizamartins321@gmail.com

${ }^{6}$ Doutora em Genética pela Universidade Estadual Paulista Júlio de Mesquita Filho, Professora Titular da Universidade Federal de Viçosa, Campus Viçosa (MG), Brasil. Email: mtavares@ufv.br
} 


\section{Lo lúdico en la Enseñanza de Biología Celular: posibilidades en la educación superior}

Resumen: Considerando las dificultades que presentan algunos estudiantes nuevos de la Universidad para comprender conceptos abstractos, este trabajo describe un curso de extensión, en el área de Biología Celular, el cual se llevó a cabo con el objetivo de contribuir al aprendizaje efectivo de un grupo de estudiantes de pregrado. estudiantes de la Universidad Federal de Viçosa (MG). El trabajo también reporta la importancia de la experiencia vivida por los estudiantes graduados que impartieron el Curso. En el mismo se utilizaron actividades recreativas diversificadas, elegidas según la temática que se abordaría. Los resultados mostraron que el proceso fue muy bien acogido por los estudiantes, ayudándoles a comprender los contenidos, a través de un proceso ameno y accesible, que permitió la construcción de conocimientos. Para los estudiantes de posgrado, la experiencia fue única y contribuyó a su formación profesional. Por lo tanto, los resultados fueron significativos para todos los involucrados.

Palabras clave: Aprendizaje significativo. Extensión universitaria. Metodologías activas.

\section{INTRODUÇÃO}

No contexto educacional brasileiro percebe-se que o ensino é majoritariamente voltado para a racionalidade técnica que objetiva a transmissão e a aplicação de teorias e técnicas científicas. Esta concepção metodológica acaba privando o estudante de métodos que incentivam a participação e a reflexão, além de não promover interação com o conhecimento (MORÁN, 2015). Por outro lado, Mertzig et al. (2020) afirmam que o mecanismo de aprendizagem é processual e dinâmico e não segue uma forma linear, por ser distinto para cada estudante. Nesse contexto, as metodologias ativas podem ser utilizadas como instrumento de ensino e aprendizagem, a fim de desenvolver as diversas características de aprendizado dos discentes (CALDARELLI, 2017). Assim, é fundamental vivenciar novas formas de ensinar e de aprender e é isso que se espera nas práticas docentes (MERTZIG et al., 2020).

Quando se pensa no lúdico é comum pensar na educação infantil. No entanto, a ludicidade pode estar presente desde a educação infantil até os cursos de pós-graduação, pois, qualquer processo de ensino e aprendizagem pode ser permeado por momentos de alegria, bem-estar e prazer (GROSSI, 2017). Ainda, o lúdico apresenta valores em todas as fases da vida humana e pode ser utilizado com fins pedagógicos, de modo a complementar as atividades teóricas (MIRANDA, 1969).

Atualmente tem sido apontada a importância dos métodos de ensino que priorizam o envolvimento dos discentes com modelos didáticos e que favoreçam a formação de novas habilidades e conhecimento crítico, em detrimento das metodologias de memorização (MORÁN, 2015). Desafios, atividades e jogos que exigem competências e informações e usam habilidades individuais e coletivas, têm sido muito utilizados como métodos de aprendizagem (MORÁN, 2015). Adicionalmente, diferentes trabalhos têm demonstrado a eficiência de abordagens ativas no ensino de biologia, a partir do uso de paródias e histórias (BACHUR et al., 2019a, 2019a; PAIXÃO et al., 2017; SILVA; TANAKA; PIRES, 2015; SOUZA et al., 2020). Diante disto, os métodos de ensino focalistas passam a ser considerados ultrapassados à medida que as metodologias acima citadas aumentam a reflexão e permitem que o estudante seja agente transformador e tenha autonomia e responsabilidade no seu processo de aprendizagem (SILVA; TANAKA; PIRES, 2015). 
Na perspectiva do lúdico, a necessidade de interação entre os discentes, durante um jogo didático torna-se presente, permitindo troca de informações, conteúdos e experiências que potencializam o pensamento crítico (CALDARELLI, 2017). O jogo não é a finalidade, mas sim o eixo que integra um conteúdo didático à aquisição de informações por meio de ações lúdicas (GROSSI, 2017). Desse modo, o cognitivo é facilmente aguçado, o que permite que a aprendizagem seja conduzida com fluidez, além de ajudar na relação professorestudante.

Considerando que as atividades interativas representam metodologias didáticas eficazes para facilitar a compreensão de conceitos abstratos relativos às ciências biológicas, em 2016, criamos um "Curso Lúdico de Biologia Celular". Este curso foi oferecido sucessivamente em 2016, 2017 e 2018. Nesse artigo, descrevemos a experiência realizada em 2018, com discentes dos cursos de graduação em Agronomia, Ciências Biológicas, Bioquímica, Enfermagem, Medicina Veterinária, Nutrição e Zootecnia, da Universidade Federal de Viçosa, Minas Gerais.

\section{OBJETIVOS}

Considerando o exposto, este trabalho descreve a experiência vivenciada por estudantes de Graduação e Pós-graduação, a partir do desenvolvimento de um curso de extensão voltado ao ensino de Biologia Celular, pautado na utilização de metodologias lúdicas. O curso teve como objetivo contribuir com a aprendizagem de alunos recém-ingressos na Universidade Federal de Viçosa. Adicionalmente, o curso almejava a formação inicial de docentes, aprofundando seus conhecimentos sobre as possibilidades de utilização de metodologias alternativas e lúdicas também no ensino superior.

\section{METODOLOGIA}

Em 2018, como nos anos anteriores, os discentes matriculados na disciplina "BIO 111 - Biologia Celular" da Universidade Federal de Viçosa foram convidados a participar do "Curso Lúdico de Biologia Celular". Eles foram informados que, diferentemente das monitorias e tutorias já oferecidas pela Universidade, o curso utilizaria ferramentas lúdicas para o ensino de biologia celular. Após as inscrições, foram organizadas três turmas, com aproximadamente 30 discentes cada. O Curso foi registrado via Comitê de Ética em Pesquisa com Seres Humanos da UFV, na Plataforma Brasil (CAAE: 65561817.8.0000.5153) e ministrado por discentes do Programa de Pós-graduação em Biologia Celular e Estrutural (mestrandos e doutorandos), sob orientação de professores que ministram a referida disciplina.

Durante o Curso, os alunos participavam de uma aula de 01h30min por semana, durante todo o semestre letivo, seguindo o cronograma da disciplina BIO 111. Ressalta-se que as atividades do Curso eram realizadas uma semana após os diferentes assuntos serem ministrados na disciplina regular, para garantir que todos os alunos já tivessem tido contato com o conteúdo, antes do mesmo ser abordado no Curso. 
A cada encontro, as aulas se iniciavam com uma breve revisão participativa, com a utilização de vídeos ou esquemas didáticos. Em seguida era executada a atividade lúdica, que podia envolver a confecção de mapas conceituais, dramatização, montagem de modelos, vídeos, confecção de poemas ou paródias, jogos diversos (adivinhação, bingo, baralho e tabuleiro) e/ou experimentos. As diferentes metodologias eram escolhidas de acordo com o tema que seria abordado: componentes químicos das células; estrutura de membranas; transporte de membranas; citoesqueleto; célula vegetal; mitocôndrias, cloroplastos e conversão de energia; estrutura do núcleo; replicação, transcrição e tradução; compartimentos intracelulares e transporte; mitose e meiose.

O interesse, a participação e a criatividade dos participantes do Curso, bem como a capacidade de trabalho em grupo dos mesmos foram avaliados de forma dinâmica, contínua e processual em cada aula, durante todo o semestre. No final do semestre foi aplicado um questionário para verificar a opinião dos discentes sobre o Curso e as metodologias empregadas (Anexo 1). Adicionalmente, compararam-se as notas obtidas nas provas da disciplina BIO 111 dos discentes que participaram do Curso, com as notas daqueles que não participaram (médias e desvio padrão). As médias foram comparadas pelo teste $t$ de Student considerando-se estatisticamente significante as diferenças com valor de P d" 0,05. Ao final do Curso, os discentes que obtiveram frequência mínima de $75 \%$ receberam certificado de participação, com a carga horária do curso.

A contribuição da experiência para os Pós-graduandos ministrantes do Curso também foi realizada de forma contínua, em reuniões semanais para análise crítica das experiências que estavam sendo vivenciadas, dificuldades e expectativas. Nessas reuniões também se discutia o assunto e as estratégias que seriam utilizadas na semana seguinte. Após essas reuniões, os pós-graduandos se organizam para rever o assunto, preparar e testar (se necessário) a próxima atividade. Muitas vezes, eles se dedicavam a elaboração e impressão dos jogos e seleção dos vídeos que seriam utilizados ou na busca de materiais e equipamentos que seriam fornecidos aos alunos, para que os mesmos desenvolvem suas maquetes, modelos, experimentos, etc.

\section{RESULTADOS E DISCUSSÃO}

Para a efetivação do processo ensino e aprendizagem é importante o conhecimento, por parte do docente, de que cada estudante é um ser único, com uma forma de aprendizado diferente do outro, necessitando de estímulos diferentes para aprender e se sentir atraído pelo conteúdo (MORÁN, 2015). Isto acontece porque o espectro da inteligência humana pode ser classificado de diferentes maneiras: sinestésico-corporal, linguístico, lógico-matemático, espacial, musical, naturalístico, intrapessoal e interpessoal (GARDNER, 1995). Tendo em vista essas características, a Teoria das Inteligências Múltiplas é uma importante justificativa para a utilização de métodos interativos no contexto educacional e a atividade lúdica ao ser valorizada e utilizada como recurso pedagógico, pode contribuir para o desenvolvimento das competências do educando (GARDNER, 1995; LIMA, 2008).

De acordo Gardner (1995) somos diferentes uns dos outros, em grande parte, porque possuímos diferentes combinações de inteligência. Neste sentido, durante o Curso Lúdico foram utilizadas metodologias interativas 
diversas, para estimular as múltiplas inteligências e as suas combinações. Na aula sobre membranas, por exemplo, utilizaram-se dinâmicas para representar sua estrutura e o mecanismo de transporte realizado pelas suas proteínas, enquanto na aula sobre replicação, os alunos foram convidados a elaborar uma dramatização que simulasse a dupla fita de DNA. Já na aula sobre mitose, fornecemos massa de modelar aos alunos, para que os mesmos representassem, com diferentes cores e formatos, as etapas do processo da divisão celular. Essa variedade de estratégias visava explorar a criatividade, o trabalho em grupo e a pro-atividade, além de estimular o aprendizado baseado na prática, pois, os alunos se tornavam os atores principais desse processo. Ressalta-se que, após confeccionar os materiais, os participantes do Curso eram incentivados a explicar para os demais alunos os resultados obtidos. De acordo com Glasser (1990), nós aprendemos quando lemos, ouvimos, observamos, discutimos o assunto com outras pessoas, executamos uma atividade e, por fim, quando ensinamos a alguém. Então, de um modo geral, durante as aulas foi possível transitar por essas diferentes abordagens, contribuindo para o aprendizado e a assimilação de conteúdos.

Essa abordagem parece ter surtido efeito, pois, durante a realização do Curso, os discentes mostraramse participativos, cada um a seu modo, realizando vários questionamentos nas aulas semanais. A ativa participação dos mesmos nas atividades ajudou a tornar as aulas mais prazerosas, dinâmicas e interativas, o que facilitou o processo de ensino e aprendizagem. Os participantes do Curso parecem concordar com estes argumentos, pois, a maioria deles classificou o Curso como "ótimo", na avaliação final.

A análise do questionário utilizado também evidenciou a importância de se utilizar diferentes atividades lúdicas, o que possibilitou a compreensão do conteúdo por um grande número de discentes. Neste sentido, o discente $\mathrm{E} 22$ ressalta que a metodologia foi eficiente quando lembra que:

[...] quando ocorria alguma dúvida sobre a matéria, lembrava das atividades [do Curso], esclarecendo algumas dúvidas.

Adicionalmente, o discente E26 diz que:

\section{[...] os conteúdos que não entendi na aula de BIO 111, eu consegui entender no Curso.}

A natureza abstrata dos processos celulares e bioquímicos, discutidos na disciplina de Biologia Celular, exige a capacidade de imaginação do discente. Dessa maneira, os jogos didáticos e outras atividades lúdicas tornaram-se alternativas viáveis e interessantes para melhorar o entendimento desses conteúdos mais abstratos. Por ser dinâmico e prazeroso, o lúdico favorece a motivação intrínseca, o desenvolvimento, a imaginação e o simbolismo como criação de significados que facilitam a aprendizagem (CAMPOS; BORTOLOTO; FELÍCIO, 2003). O discente E49 parece concordar com o fato de que as atividades lúdicas auxiliam no entendimento de assuntos mais abstratos, tornando mais "palpável" e concreto os processos celulares, ao relatar que: 
[...] o desenvolvimento de atividades, brincadeiras e jogos facilitou a assimilação do conteúdo, que é muito teórico.

Em consonância com essa percepção, o discente E57 ressalta que:

[...] a metodologia lúdica teve efeito direto na forma de aprendizado porque apresentou o conteúdo sobre outra perspectiva.

O fato de as aulas serem mais dinâmicas também foi considerado como tendo um efeito positivo no processo de aprendizagem, pelo discente E01:

Muitos dos recursos utilizados eram muito mais explicativos do que o padrão de aula. Interagir com a matéria me fez aprender verdadeiramente a maioria da matéria, ao invés de apenas memorizar para fazer a prova.

No mesmo sentido, os discentes E04 e E85 mencionam, respectivamente, que:

[...] as formas de apresentação do conteúdo, usando ferramentas visuais, virtuais e interativas facilita a compreensão.

[...] o método dinâmico de ensino estimula o pensamento e a criatividade [...].

Esses depoimentos evidenciam que a educação, quando sustentada pelo processo de construção coletiva e pela participação, torna-se mais efetiva do que as aulas teóricas que se desenvolvem como um monólogo, com os discentes sendo meros receptores de informações. Sendo assim, o professor deve utilizar diferentes abordagens, de forma a atrair a atenção do estudante para o conteúdo que está sendo abordado (LIMA \& PESSOA, 2007). Porém, para que isso aconteça, há necessidade de mudanças didáticas que façam com que o discente deixe de ser agente passivo e passe a construir e reconstruir, sob orientação do professor, novos conceitos (ZUANON; DINIZ; NASCIMENTO, 2011). No caso específico do Curso Lúdico de Biologia Celular, todos os participantes (100\%) do Curso consideraram que as atividades realizadas ajudaram no entendimento dos conteúdos, evidenciando que os mesmos conseguiram perceber a importância da metodologia utilizada para seu aprendizado. Além disso, foi destacado pelos discentes que esse aprendizado refletiu no seu desempenho nas avaliações da disciplina correspondente. Os discentes E44 e E30, por exemplo, relataram, respectivamente, que:

[...] muitas atividades nos ajudaram a relacionar o seu conteúdo com a matéria, o que ajudou na realização da prova.

[...] me ajudou a compreender mais sobre a matéria e a ter um bom resultado nas provas.

Essa percepção dos discentes participantes do Curso pode ser confirmada pela análise comparativa das suas notas com as notas daqueles matriculados na disciplina e que não participaram do Curso. Conforme pode ser observado na Figura 1, as notas do primeiro grupo foram, em média, 6,14\%, 11,54\% e 10,81\% maiores do 
que a dos discentes que não fizeram o Curso, na primeira, segunda e terceira avaliações, respectivamente. Consequentemente, as notas finais desse grupo também foram maiores $(8,57 \%)$ do que as dos discentes que não participaram do Curso.

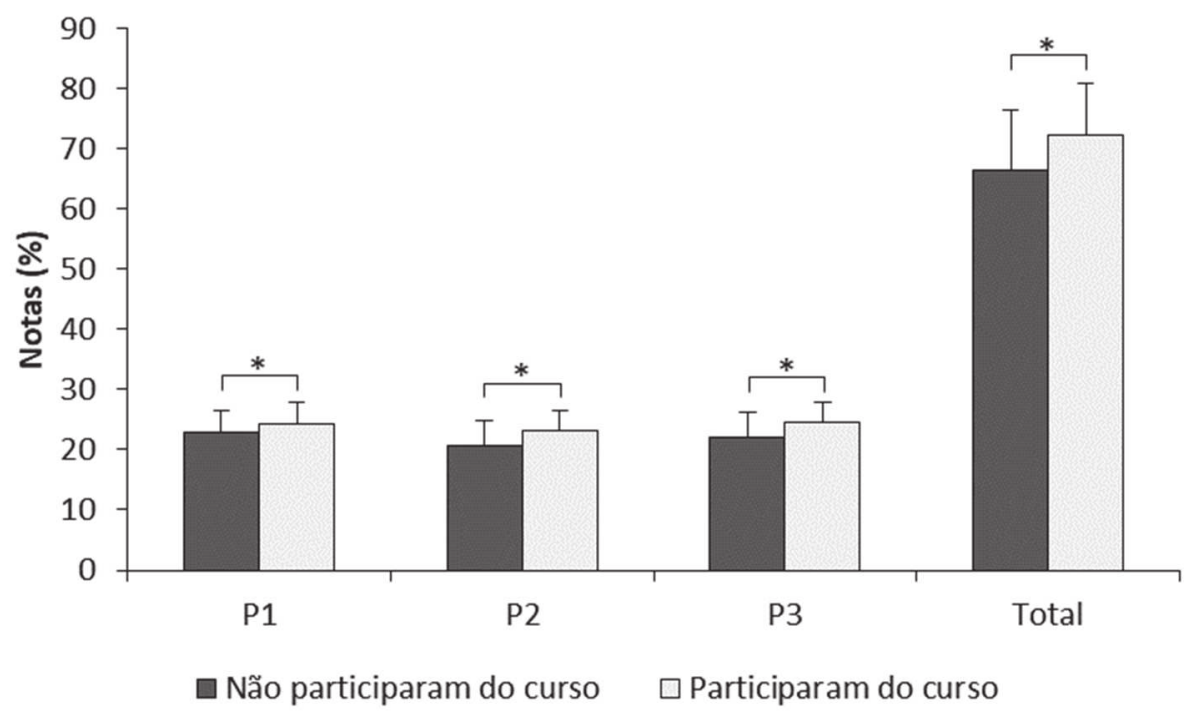

Figura 01- Valores médios e desvios padrão das notas dos discentes que participaram (n=99) ou não (n=646) do Curso Lúdico de Biologia Celular, obtidos nas provas 1 (P1), 2 (P2) e 3 (P3) e nota final (Total) dos dois grupos, na disciplina BIO 111. *: médias estatisticamente diferentes.

Fonte: As autoras.

Do mesmo modo, as análises realizadas evidenciaram uma redução de 40,78\% na taxa de reprovação dos discentes que participaram do Curso, em comparação com a taxa de reprovação dos discentes que não participaram do mesmo. Assim, pode-se supor que a participação dos discentes no Curso Lúdico de Biologia Celular contribuiu para que os mesmos obtivessem bons resultados na disciplina BIO 111. Tal fato pode refletir a maior compreensão e assimilação dos conteúdos ministrados, pois, atividades lúdicas e interativas exploram outras formas de ensinar e estímulos diversos para a construção do aprendizado (AZEVEDO et al., 2019). Complementando a visão dos participantes do Curso sobre as atividades desenvolvidas, quando questionados se indicariam o curso para futuros discentes da disciplina, eles responderam que:

Sim. Minhas notas de BIO111 foram muito maiores do que eu esperava, e creio que isso se deva principalmente ao curso. É muito bom para revisar a matéria e ter outras perspectivas do conteúdo [...]. E01

Sim, porque ajuda muito o entendimento das matérias, lembro das aulas e atividades na hora das provas. E06

Sim. Pois além de ser uma maneira diferente e prazerosa de aprender é totalmente voltada para a disciplina que cursamos, é benéfico tanto para a compreensão da matéria assim como para o crescimento do conhecimento. E10

Sim, pois é um curso que esclarece a matéria dada em sala, além de ajudar na fixação da mesma com atividades descontraídas e muito interessantes, no qual se aprende de forma leve e divertida. E33 
Dessa maneira, entendendo a Universidade e os Programas de Pós-graduação como espaços formadores de futuros docentes, se faz necessária a reflexão sobre novas formas de Educação Superior. Considerando que a preocupação com uma educação significativa tem sido pauta frequente em debates e pesquisas em educação (BRITO \& CAMPOS, 2019; DE SOUZA et al., 2020; MERTZIG et al., 2020; SOUZA et al., 2020), a valorização do lúdico como premissa para uma educação de qualidade é evidente. Porém, o que se observa é que ainda seguimos, da Educação Básica até o Ensino Superior, reproduzindo uma carência de análise crítica, reflexão e, principalmente, prazer no aprender e ensinar. Fica então, a falsa ideia de que aprender é antônimo de lazer, o que é uma falácia, pois, sabe-se que a aprendizagem só será significativa quando fizer sentido aos envolvidos e quando os mesmos puderam associar novos aprendizados aos seus conhecimentos prévios (VERISSIMO \& SANTOS, 2016).

No cenário atual em que o mercado de trabalho tem se mostrado cada vez mais competitivo e concorrido, os profissionais que durante sua formação tiverem esse estímulo à criatividade, ao desenvolvimento de novas habilidades e competências serão profissionais diferenciados (COVOS et al., 2018). Nesse contexto, a participação dos pós-graduandos no Curso Lúdico de Biologia Celular contribuiu para a formação de professores questionadores, que ousam e estimulam a inclusão de novas abordagens e do lúdico no ensino voltado à graduação. Tais reflexões foram percebidas pelos pós-graduandos que ministraram o curso lúdico, sendo que um deles comenta que:

\footnotetext{
Me graduei em um curso de bacharelado em que não tive nenhum contato com disciplinas de licenciatura. O Curso Lúdico foi um espaço criado para nós, pós-graduandos, termos contato com a sala de aula e desenvolver algumas das habilidades necessárias para o ensino. Dessa forma, o curso me ajudou não somente com a biologia celular, mas com aspectos e técnicas educacionais que posso utilizar no ensino de qualquer disciplina. Foi minha primeira experiência em sala de aula enquanto professor, antes mesmo do estágio em ensino obrigatório da pósgraduação e foi uma experiência muito cara pra mim, que guardo com grande carinho, por ter confirmado as minhas expectativas e o sonho da carreira enquanto professor. As aulas eram preparadas em grupo, com os colegas pós-graduandos e também com professores do curso. Pensávamos as aulas em todos os seus momentos, desde a revisão até os momentos de aprendizado de conteúdo novo ou reforço do conteúdo revisado, utilizando metodologias ativas, de forma que todos os professores fossem capazes de desenvolver a mesma atividade com sua turma. As práticas eram variadas, de forma a tentar atingir todo o tipo de perfil de aluno, entendendo que as pessoas tem formas diferentes de aprender. Não eram todas as aulas que cativavam todos os alunos, nem mesmo todos os professores, mas isso é normal, pois, como falei, cada um tem um jeito de aprender as coisas. De toda forma, todos participavam. O curso foi uma experiência importante na minha formação enquanto professor, ajudando a suprir necessidades metodológicas e sendo um ambiente de treino e aprendizado, de interação com os alunos e de feedback imediato, com o diálogo constante com os alunos e com os colegas professores e nossa orientadora.
}

Outra pós-graduanda comenta que:

O Curso Lúdico em Biologia Celular foi minha primeira experiência efetiva com o ensino superior. Tivemos dedicação e comprometimento com o preparo das aulas para que, de forma lúdica, atingisse as exigências de uma disciplina de uma universidade de excelência. Apesar de 
participação voluntária, algo que sempre me fascinava era a aceitação e dedicação dos estudantes com o nosso curso. No entanto, esse interesse era algo compreensível quando observávamos nós, ministrantes do curso, pois também estávamos lá por vontade. Diferentemente do nosso "Estágio em Ensino", experiência obrigatória com o ensino superior durante a pósgraduação, eu me senti inteiramente responsável pelo aprendizado daqueles estudantes. Acredito que isso foi devido ao fato que, apesar de seguirmos o conteúdo estabelecido para a disciplina de Biologia Celular, era a nossa responsabilidade de criar metodologias e ferramentas atrativas e, ao mesmo tempo, aplicá-las de maneira efetiva. $O$ "Curso Lúdico em Biologia Celular” é uma experiência com a docência no ensino superior que faço questão de destacá-la no meu currículo e entrevistas profissionais. Essa experiência foi eficiente tanto para o aprendizado dos alunos quanto para o meu desenvolvimento profissional, uma vez que viso uma carreira centrada, principalmente, no ensino superior.

Outra pós-graduanda concorda com os dois colegas acima ao afirmar que o curso lúdico fui fundamental na sua formação docente:

\begin{abstract}
A participação no Curso Lúdico foi fundamental para minha formação enquanto docente. Durante a graduação cursei licenciatura, fui monitora de disciplinas de bioquímica/biologia molecular e ao longo do mestrado ministrei aulas em um cursinho popular. Então, quando entrei para o projeto eu já tinha certa experiência com o ensino em diferentes turmas e faixas etárias. No entanto, a participação nesse projeto foi a minha primeira oportunidade de vivenciar, construir $e$ aplicar metodologias ativas no ensino de biologia. Fiquei encantada com a possibilidade de se utilizar ferramentas lúdicas com os alunos da graduação. É uma experiência incrível, que agora eu levo como bagagem para aplicar sempre que possível com os meus alunos. Os resultados e a receptividade foram muito positivos! O projeto me permitiu explorar a criatividade e estreitar relações com os alunos, uma vez que a dinâmica das aulas favorecia uma atenção e um contato maior com cada aluno. Eé válido ressaltar que a infraestrutura e apoio da UFV e da professora coordenadora, foram fundamentais para a execução e continuidade do curso!
\end{abstract}

Dessa mesma forma, foi unânime o reconhecimento sobre a importância do curso para a formação de professores, pós-graduandos em Biologia Celular. Outra pós-graduanda ainda comenta que:

O Curso Lúdico foi muito importante para minha formação acadêmica porque estimulou a minha criatividade e me ajudou a pensar na forma mais didática de se trabalhar um conteúdo, sempre buscando otimizar o aprendizado do aluno. Trabalhar os conceitos de biologia celular de forma lúdica foi desafiador e, ao mesmo tempo, prazeroso porque era gratificante ver o envolvimento dos alunos com as atividades propostas e o aprendizado alcançado por meio delas. A equipe de trabalho era excelente, os pós graduandos prezavam pela qualidade do curso além da boa convivência e do apoio interpessoal. Os alunos participantes do curso eram interessados, participativos e isso incentivava a equipe a sempre oferecer um trabalho melhor. A experiência foi positiva em sua totalidade.

\title{
CONCLUSÕES
}

Na concepção dos discentes da graduação que participaram do Curso Lúdico de Biologia Celular, o emprego de metodologias diversificadas aliado à oportunidade de interagir com recursos pedagógicos construídos/ pensados pelos próprios graduandos representou uma forma de "aprender mais", contribuindo para o processo de ensino e de aprendizagem. Desta forma, o Curso Lúdico e as metodologias utilizadas contribuíram para a redução das reprovações no primeiro ano do ensino superior. 
Por outro lado, a participação dos discentes da pós-graduação em todas as etapas do processo, desde a escolha das estratégias que seriam utilizadas para se abordar os variados conteúdos, passando pelos processos de preparação e desenvolvimento das atividades, e culminando com a análise dos resultados obtidos, sem dúvida contribuiu para a formação inicial destes futuros professores. Não se pode esquecer que durante as reuniões semanais os pós-graduandos eram incentivados a discutir as necessidades de ajustes e os aprendizados decorrentes das atividades executadas, o que os levava à reflexão das ações desenvolvidas e, consequentemente, maior apropriação de conhecimentos e práticas. Esse trabalho em grupo, portanto, representou uma experiência única, que contribuiu sobremaneira para o pensar sobre metodologias de ensino que estimulem a ativa participação e aprendizado dos alunos. Portanto, os resultados foram significativos para todos os envolvidos (discentes da graduação e pós-graduação).

\section{AGRADECIMENTOS}

Agradecemos à Universidade Federal de Viçosa (UFV) e ao Departamento de Biologia Geral pela disponibilização dos recursos necessários à realização do "Curso Lúdico de Biologia Celular”' (CUR-310/2016, CUR322/2017 e CUR-257/2018). Agradecemos também, a todos os professores que ministram a disciplina Biologia Celular (BIO 111), aos graduandos e pós-graduandos que, voluntariamente, participaram do referido Curso.

\section{REFERÊNCIAS}

AZEVEDO, S. B.; PACHECO, V. A.; SANTOS, E. A. DOS. Metodologias ativas no ensino superior. Revista Docência do Ensino Superior, v. 9, p. 1-22, 2019.

BACHUR, T. P. R. et al. Paródias e contação de história: formas lúdicas de ensinar parasitologia no ensino superior. Revista de Ciências Médicas e Biológicas, v. 18, n. 1, p. 79, 2019a.

BACHUR, T. P. R. et al. Paródias e contação de história: formas lúdicas de ensinar parasitologia no ensino superior. Revista de Ciências Médicas e Biológicas, v. 18, n. 1, p. 79, 2019 b.

CALDARELLI, P. G. A importância da utilização de práticas de metodologias ativas de aprendizagem na formação superior de profissionais da saúde. Revista Sustinere, v. 5, n. 1, p. 659-677, 28 jul. 2017.

CAMPOS, L. M. L.; BORTOLOTO, T. M.; FELÍCIO, A. K. C. A Produção De Jogos Didáticos Para O Ensino De Biologia: Contribuições E Perspectivas. Caderno dos núcleos de Ensino, v. 39, n. 5, p. 561$563,2003$.

COVOS, J. S. et al. O Novo Perfil De Alunos No Ensino Superior, E a Utilização De Jogos Lúdicos Para Facilitação Do Ensino Aprendizagem. Revista Saúde em Foco, p. 62-74, 2018.

GARDNER, H. Estruturas da Mente: A teoria das Inteligencias Múltilpas. $2^{a}$ edição ed. Porto alegre: Penso, 1995. 
GLASSER, W. The Quality School: Managing Students without Coercion. New York, NY - USA: Harper and Row Publishers, Inc, 1990.

GROSSI, M. G. R. O lúdico na aprendizagem de alunos de cursos técnico, graduação e mestrado: relatos de experiências. Revista Ibero-Americana de Estudos em Educação, v. 12, n. 3, p. 1689-1709, 2017.

LIMA, J. M. DE. O Jogo Como Recurso Pedagógico No. São Paulo: Cultura Acadêmica Editora, 2008.

LIMA, T. C. F. DE; PESSOA, A. C. R. G. Dificuldade de aprendizagem: principais abordagens terapêuticas discutidas em artigos publicados nas principais revistas indexadas no LILACS de fonoaudiologia no período de 2001 a 2005. Revista CEFAC, v. 9, n. 4, p. 469-476, 2007.

MERTZIG, P. L. L. et al. Reflexões sobre práticas coletivas e metodologias ativas no ensino superior. Revista Aproximação, v. 02, p. 45-50, 2020.

MIRANDA, S. DE. No Fascínio do jogo, a alegria de aprender. Linhas Críticas, v. 8, n. 14, p. 21-34, 1969.

MORÁN, J. Mudando a educação com metodologias ativas. Convergências Midiáticas, Educação e Cidadania: aproximações jovens, v. II, p. 15-33, 2015.

PAIXÃO, G. C. et al. Paródias no ensino de microbiologia: a música como ferramenta pedagógica. Revista Eletrônica de Comunicação, Informação e Inovação em Saúde, v. 11, n. 1, p. 1-12, 2017.

SILVA, L. V. S.; TANAKA, P. S. DE L.; PIRES, M. R. G. M. BANFISA and (IN) DICA-SUS in health undergraduate education: playing and learning construction. Revista Brasileira de Enfermagem, v. 68, n. 1, p. 124-130, 2015.

SOUZA, L. S. DE; SANTOS, D.; MURGO, C. S. Metodologias Ativas na Educação Superior em Saúde Brasileira: Uma Revisão Integrativa frente ao Paradigma da Prática Baseada em Evidências. Revista Internacional de Educação Superior, v. 7, p. 1-32, 2020.

SOUZA, P. M. B. DE et al. Metodologias ativas de ensino e aprendizagem no ensino da Anatomia Humana: Uma experiência usando massa de modelar e outras ferramentas de comunicação em um projeto de monitoria. Brazilian Journal of Development, v. 6, n. 6, p. 41834-41843, 2020.

VERISSIMO, A. C. B.; SANTOS, A. M. DOS. Por que pensar o lúdico na universidade? Anais do XV Seminário Internacional de Educação. Anais do XV Seminário Internacional de Educação. Novo Hamburgo, RS: Universidade FEEVALE, 2016

ZUANON, Á. C. A.; DINIZ, R. H. S.; NASCIMENTO, L. H. DO. Construção de jogos didáticos para o ensino de Biologia: um recurso para integração dos alunos à prática docente. Revista Brasileira de Ensino de Ciência e Tecnologia, v. 3, n. 3, p. 49-59, 2011. 